Article

\title{
Innovation Ecosystem of CNG Vehicles: A Case Study of Its Cultivation and Characteristics in Sichuan, China
}

\author{
Ling Ding ${ }^{1,2}$ and Jinxi Wu ${ }^{2, *}$ \\ 1 Chinese Academy of International Trade and Economic Cooperation, Ministry of Commerce, \\ Beijing 100710, China; dingling98@163.com \\ 2 School of Social Sciences, Tsinghua University, Beijing 100084, China \\ * Correspondence: wujx02@mail.tsinghua.edu.cn; Tel.: +86-010-6279-8443-23
}

Received: 17 October 2017; Accepted: 4 December 2017; Published: 25 December 2017

\begin{abstract}
Under the constraints of resources and environment, China is eager to cultivate a new industrial system with ecological characteristics in light of local circumstances. This paper selects the innovation ecosystem of Compressed Natural Gas (CNG) vehicles in Sichuan, China as the objective of the case study to explore its cultivation and characteristics. The theoretical significance lies in three areas. Firstly, the cultivation path of the CNG vehicle innovation ecosystem is manifested. Secondly, the symbiotic process model among the communities within the CNG vehicle innovation ecosystem is found. Thirdly, the substitutive process model of the CNG vehicle innovation ecosystem is discovered, which reveals the substitutability among innovation ecosystems, the communities of similar products, and the enterprises of similar products. This paper is of theoretical, practical, and political significance for the development of a CNG vehicle innovation ecosystem in emerging markets in terms of regional energy security and emission reduction.
\end{abstract}

Keywords: innovation ecosystem; CNG vehicles; cultivation path; strategic management

\section{Introduction}

A vibrant innovation ecosystem (IE) can offer enterprises an innovation environment of "tropical rain forests" where the internal interaction has much in common [1]. Under the constraints of resources and environment, China is eager to develop a new industrial system with ecological characteristics in light of local circumstances [2]. However, based on the literature review, this study finds that there have been insufficient theoretical contributions in the study of the cultivation and characteristics of regional IEs in resource-rich areas. In 2015, natural gas accounts for nearly $24 \%$ of the global primary energy consumption, while the Chinese counterpart only accounts for $5.8 \%$, less than $1 / 4$ of the world average. Many countries in the world are developing the natural gas vehicle industry for energy security and emission reduction. Recently, China follows to develop the natural gas vehicle industry to boost natural gas consumption. Up to 2014, the amount of Chinese Compressed Natural Gas (hereafter referred to as CNG) vehicles had been 4.411 million, and the amount of gas stations had been 4455 , both ranking the first in the world.

Sichuan province is the leading region in China initiating the development of CNG vehicle technologies and CNG filling stations, and continuously developing CNG vehicle industry based on its unique resource advantages. This study takes the CNG vehicle IE of Sichuan province as the object of case study and tries to discuss the following questions:

(1) How is Sichuan's CNG vehicle IE cultivated?

(2) What are the characteristics of Sichuan's CNG vehicle IE? 
The study is of theoretical and political significance for the region with the resource advantage to develop CNG vehicle IE for energy security and emission reduction.

\section{The Literature Review of IE}

\subsection{Origin and Concept of IE}

The understanding of the conception of IE in academia is a gradually deepening process. Ander thought that the IE is a kind of cooperative arrangement that combines multiple enterprises' products together to customers [3]. Lumoa-aho and Halonen defined the IE as a persistent or temporary system that consists of various innovation organizations interacting, communicating, and promoting innovation in the ecological environment [4]. Zahra and Nambisan considered that IE is a loose but interconnected enterprise network where every enterprise develops in coordination with the help of the innovation platform and depends on each other for the whole's efficiency and survival [5]. Adner and Kapoor revealed that IE not only contains the innovation of focal enterprises, but also that of their upstream suppliers, downstream customers, and complementors. It is impossible to offer valuable products and services without complementary cooperation with various cooperative partners, and the complementary network organization is called IE [6]. Chinese scholars Zeng et al. thought that IE derived from the organization's deepening cognition of the innovation system [7].

This study defined innovation ecosystem as "a network system consisting of the communities of governments, product enterprises, complementary products enterprises, and customers, which interact, communicate, or promote innovation in order to create valuable new products". CNG vehicle innovation ecosystem is defined as a network system consisting of the communities of governments, CNG vehicle product enterprises, CNG complementary products enterprises, and customers, which interact, communicate, or promote innovation in order to create valuable new CNG vehicle products.

\subsection{Structure and Characteristics of IE}

Scholars have different points of view on describing the structure or composition of IE. According to Rohrbeck et al., IE is composed of three subsystems, namely the research subsystem, development subsystem, and application subsystem [8]. Enterprises span the boundary of research and development between organizations to obtain external knowledge resources and improve innovation competence [8]. Birol and Göktaş explained the composition of IE as a cluster, the university-industry cooperation, and a culture to innovate [9]. Using network analysis, Rubens et al. further revealed the role of the investment companies as resource routers in China's IE [10].

IE is featured with some characteristics. Curley and Salmelin pointed out that today's innovation success is a combination of IE with quick adoption of new and better products and services that are created by many participants [11]. For materials (such as product-focused improvement), many projects or proposals are still inappropriate and expensive due to the disadvantages of the "shelter" in IE [12]. Autio et al. revealed the importance of innovation context for an enterprise [13].

\subsection{Mechanism and Building of IE}

Scholars have demonstrated some mechanisms of IE. Hansen et al. argued that different players connect and interact within IE [14]. By re-using and re-structuring the internal platform and assets of an enterprise, its suppliers, or both, the enterprise may become more profitable. In a similar vein, an industry platform may facilitate the re-structuring of a new round of innovative cooperation within the supply chain [15]. Zhang et al. expounded the relationship between platform enterprises and supporting enterprises [16]. Platform enterprises maintain the leading position in platform IE on the basis of trust and control mechanisms, while supporting enterprises are involved in developing supporting products. When platform enterprises and supporting enterprises complement their strength and resources, supporting enterprises invest more on research and development (R\&D), and the revenue sharing coefficient is increased along with the increased financial support by platform 
enterprises. In contrast, when resources and strength are substitutive between platform enterprises and supporting enterprises, even if platform enterprises invest more, supporting enterprises may be less active in R\&D activities, leaving the revenue sharing coefficient decreased.

Scholars also examined what the influential factors are in building and maintaining IE. Arimoto and Levien argued that along with the investment on manpower and finance, knowledge creation and long-term basic research was the investment on innovation in a sustainable IE [17]. The regional cluster will create new products or services and increase enterprise profit and social welfare through collaboration between university and industry. In an industry with frequent and rapid changes, enterprises need to be highly cooperative to cope with the continuously changing market expectations. The pressure from the market forces the enterprise to be more innovative, and resort to more external resources for the sake of profits [18]. The total cost of social R\&D is the main ecological factor influencing regional GDP, and the number of patents is the main ecological factor influencing the value of high and new technology industry [19]. Collaborative innovation network is an innovation ecosystem of automatic cycle [20]. Concerning the evolution of innovation ecosystems, the unique value is to keep its own health and vitality [21]. The cultivation of an innovation ecosystem is regarded as the most advantageous environment to adapt to all kinds of expansive visions [22]. Organizational resource, network resource, and system resource interact and co-evolve in the cultivation process of innovation ecosystem [23].

Existing theoretical research provide significant inspiration and foundation for this study. However, there have been insufficient theoretical contributions to the cultivation and characteristics of regional IE of resource-rich areas, leaving much room for in-depth research.

\section{Research Design and Data Collection}

\subsection{Research Method}

This paper adopted the case study method. Case study is an important research method in management and organizational studies. The case study method is adopted in this research for the following reasons. First, the generalization method is a suitable way to study questions involving "how" [24]. One key point of this paper is to discuss how Sichuan province cultivates its CNG vehicle IE. Second, the analytic generalization principle from case to theory is suitable for exploring and explaining the research phenomena above. The phenomena of cultivation and characteristics of CNG vehicle IE are complex and multifaceted, leaving relative factors and processes still unclear. Therefore, it is hard to answer the above research questions by using quantitative methods. Third, the case study method is very suitable for research aiming at an overall process [25]. CNG vehicle IE in this paper is featured with characteristics of the overall process.

\subsection{Research Case Selection}

This research selects Chinese Sichuan province's CNG vehicle IE as the case for the reason that it reflects the following three principles of case selection:

First of all, the case selection takes into account both importance and representativeness [26]. Sichuan, as the leader of CNG vehicle IE with rich CNG resources in China, can represent the practices in the CNG vehicle industry with the same characteristics. Sichuan province is the first region in China to develop CNG vehicle technologies and CNG filling stations. Over the past 27 years, the government and enterprises of Sichuan province continuously cultivated the CNG vehicle IE based on its advantage of resources. Above all, the cultivation and characteristics of the resource-rich area's IE are obvious.

Secondly, the selection of research sample follows the principle of theoretical sampling. The choice of case is based on the need to fill existing theoretical gaps or develop new theories rather than statistical sampling [27]. The cultivation and characteristics of IE are important topics of academic concern. Existing theoretical research provides significant inspiration and foundation for the concepts, 
structures, characteristics, mechanisms, and establishment of IE. However, the theoretical background is insufficient in the cultivation and characteristics of a resource-rich area's IE from an evolutionary perspective. The research on Sichuan CNG vehicle IE tries to discover of how the communities of the governments, enterprises, and so on practice the symbiosis innovation to cultivate an IE for a resource-rich area. It helps to improve the IE theory.

Thirdly, the case selection takes into account the consistency principle of theory and research object. The author team who attended the field surveys is deeply impressed by the importance of IE's cultivation process for the rapid growth of Sichuan province's CNG vehicle industry. Since the 1950s, Sichuan province has been promoting the development of CNG vehicle industry. The data is abundant and relatively integrated.

\subsection{Research Tactics and Data Collection}

In the aspect of study tactics, this research followed a standard case study process: literature review, draft design and data collection, and data analysis [28,29]. First, we collected and reviewed the literature of IE theory and confirmed the research questions and targets. Second, during the stage of draft design and data collection, we specified the methods and tactics of the interview outline design for data collection. Third, we implemented the iteration cycle in the data collection and analysis stage.

In the literature review, this research collected and studied relevant information to confirm the nature of exploratory research and research problems of this paper [28,29]. It was found that the key elements of the existing research lack an evolutionary perspective in the cultivation and characteristics of IE for a resource-rich area. Accordingly, this study sets "the in-depth research of the CNG vehicle IE of a resource-rich area from the perspectives of the IE' cultivation and characteristics" as the research target.

In terms of draft design, modeling, and data collection, this study is led by interview and observation, and is supplemented by documents and archives [29]. First, in order to get the whole picture of practical activities of Sichuan CNG vehicle IE, the interview outlines were designed. Second, the study team conducted formal and informal in-depth interviews with the provincial government of Sichuan, the municipal governments of Chengdu, Mianyang, and Luzhou, the enterprises of Shudu Bus, Yema car, and Yajun van, the local taxi drivers, and the vehicle researchers in research institutes. Third, the data was collected through the government units, Internet, published papers, and books. Finally, based on multiple data sources and interviewees, the reliable data was screened out by using the triangulation method $[28,29]$.

According to the literature review and data collection, the logic of data analysis is as follows: First of all, it was based on the view of IE, arranging the three phases of practice for the cultivation of Sichuan CNG vehicle IE. Data were reflected in the case description part of this paper. This is an important part of case study that gives readers a clear data linkage. Secondly, it analyzed the cultivation path of the CNG vehicle IE. Finally, it explores the characteristics of the CNG vehicle IE. The case study focuses on the continuous theoretical exploration of data for a mature analysis [29].

\section{Case Description: Three Phases of the IE Cultivation}

CNG vehicles have been developed in Sichuan for decades. The cultivation process of its IE can be summed up as the following three typical phases.

\subsection{Phase 1: The Birth of Sichuan CNG Vehicle Industry (1990-2000)}

In the 1950s, the Sichuan Petroleum Administration Bureau, a local enterprise, and other local enterprises successfully developed CNG vehicles, initiating the development of Chinese CNG vehicles. However, the 1950s did not witness sustainable development because of technologies, petroleum prices, cognition, and other reasons [30]. In 1990, the CNG vehicle developed by the Sichuan Petroleum Administration Bureau was granted with three national patents, and was regarded as a national new 
product. The gas stations constructed by the Sichuan Petroleum Administration Bureau supplied the CNG complementary products for the CNG vehicles.

In the following 10 years, the Sichuan provincial government promoted CNG vehicles to the whole province and the whole country. In 1993, the projects of Sichuan CNG vehicle and gas stations were approved as important projects for the promotion of national science and technology. In 1994, the project was among Sichuan province's torch programs and Chongqing municipality's high-tech projects, and was regarded as an energy-saving and environment-conservation project of Sichuan province, one of the top 10 National Technological Achievements promoted in the provincial and national level [31]. Up to September 1995, Sichuan built 25 CNG filling stations and popularized more than 1300 CNG vehicles [32]. In 1996, it constructed CNG vehicle gas stations in 14 counties and cities, such as Chengdu, Nanchong, Zigong, and Chongqing [33], with the issuing of The Technical Conditions of CNG Vehicles and The Technical Conditions of CNG Vehicle Stations by the provincial government. In 1999, Chengdu became one of the 12 pilot cities (regions) of clean energy vehicles in China, which helped the Sichuan CNG vehicle industry obtain a high-speed development.

\subsection{Phase 2: The Extension of Sichuan CNG Vehicle Industry (2001-2010)}

In the 2000s, the Sichuan CNG vehicle industry entered a phase of rapid extension. In 2001, Sichuan province formed a streamlined industrial production, which contained the research and production of natural gas and CNG vehicles, and the number of CNG vehicles and gas stations in the province reached 25,000 and 81, respectively [34]. In 2003, the project of the popularized application of CNG for diesel buses was approved by the Transportation Bureau of Sichuan provincial government.

The rapid development of the CNG vehicle industry in Sichuan province benefits from the advantageous price of oil and CNG as shown in Figure 1. Domestic gasoline prices increased rapidly in 2003-2008 with the increasing international crude oil price. According to the U.S. Energy Information Administration, U.S. crude oil price had been hovering around $\$ 15 /$ barrel in the 20 years before early 2003. In early 2004, U.S. crude oil price topped $\$ 30 /$ barrel, rising rapidly year by year. By 2008 , U.S. crude oil price had soared to $\$ 128 /$ barrel. According to our survey, the National Development and Reform Commission advised that the price ratio of natural gas and petroleum be adjusted to $0.75: 1$ in 2007, so that the price of CNG for vehicles increased about $0.3-0.5$ yuan $/ \mathrm{Nm}^{3}$. In 2010, the National Development and Reform Commission alerted to raise the wellhead price of natural gas, and some provinces including Sichuan raised the price by about $1-2$ yuan $/ \mathrm{Nm}^{3}$.

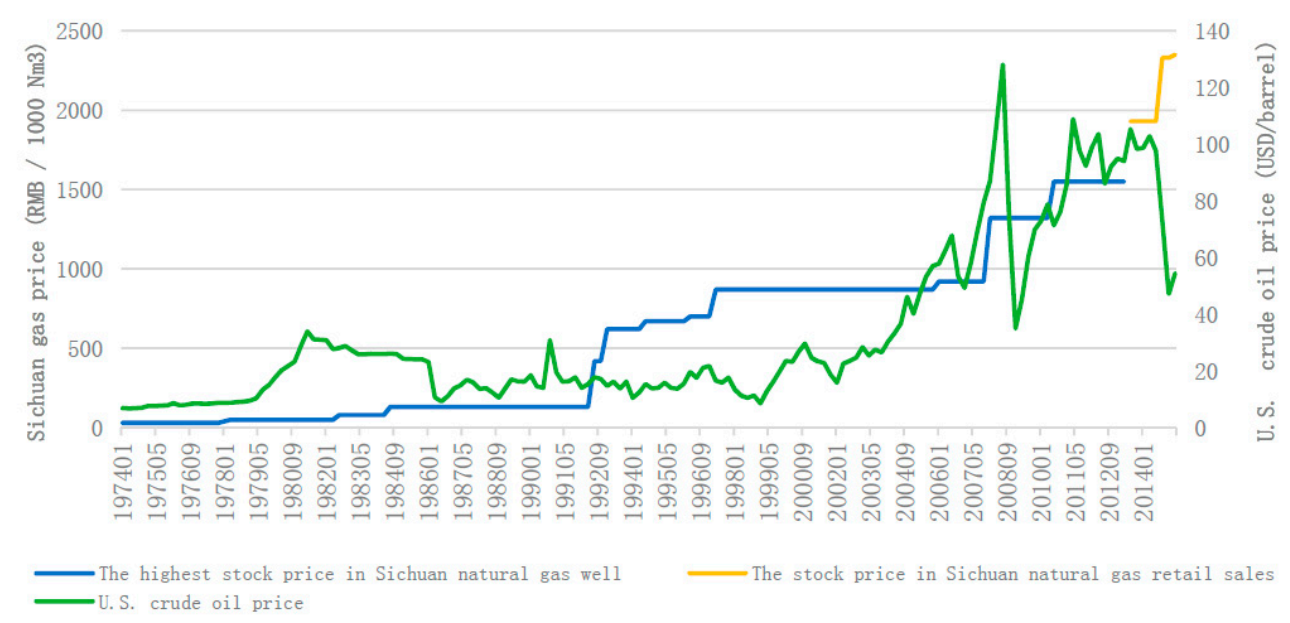

Figure 1. Price trends of the United States' crude oil and Sichuan's natural gas in the past 42 years.

With the increase of China's natural gas price, the amount of natural gas for chemical use decreased, which caused excessive capacity in main provinces producing natural gas (the total output of gas in Shanxi, Xinjiang, and Sichuan accounted for more than seventy percent in China). Meanwhile, 
gasoline prices increased. Therefore, it was an inevitable choice for Sichuan province to strengthen policy support on CNG vehicle development and quicken the pace of supporting facilities' construction. Since the People's Republic of China was founded, there have been 13 Five-Year Plans, and the thirteenth Five-Year Plan was started in 2016). The Five-Year Plan mainly makes plans for important construction projects at national level, the distribution of productivity, and the ratio of the national economy, defining objectives and directions for the vision of national economic development. In the period of the Eleventh Five-Year Plan (2006-2010), the industrialization and technology innovation of Sichuan CNG vehicles has achieved great progress. At the end of 2010, the number of local enterprises engaged in CNG vehicle production, equipment manufacturing, vehicle re-equipment and repair, and gas stations, reached over 400, while the number of local CNG vehicle ownership accounted for $8.38 \%$ of national vehicle volume [35]. Sichuan built 247 CNG filling stations in total with 252,000 CNG vehicles used, making the amount and promotion rank the first in China [36].

\subsection{Phase 3: The Formation of Sichuan CNG Vehicle IE (2011-Now)}

In the period of Twelfth Five-Year Plan (2011 2015), Sichuan CNG vehicle IE developed continuously. By the end of 2013, Sichuan had put nearly 400,000 CNG vehicles into use, and had built around $320 \mathrm{CNG}$ filling stations. The accumulative output value of CNG vehicle industry was 78.8 billion yuan, and there were 1.82 million tons of harmful gas reduced, saving 34.5 billion yuan for fuel. In 2014, Sichuan formed a CNG filling station network which covered 20 cities (states) and over 100 counties. From 2014 to 2015, the domestic and international petroleum price dropped dramatically. The domestic price difference declined between natural gas and petroleum prices. Therefore, the price of CNG was decreased with the price of petroleum of Sichuan province by the government. The price reduced three times from $¥ 4$ yuan $/ \mathrm{Nm}^{3}$ in 2014 to $¥ 3$ yuan $/ \mathrm{Nm}^{3}$ in November 2015 .

However, in the face of the decline in international crude oil price and the subsidy policies of central government on the electric vehicles, Sichuan CNG vehicle policy dividends and price dividends were relatively reduced in this phase. Therefore, Sichuan CNG vehicle IE was squeezed to some extent by the fuel IE and the electric vehicle IE. According to the data of the U.S. Energy Information Administration (refer to Figure 1), the U.S. crude oil price in 2009 fell sharply to $\$ 35 /$ barrel, then quickly rose to $\$ 109 /$ barrel in 2011 . From 2011 to 2013 , the crude oil price was stable at the high range of $\$ 85 \sim \$ 110 /$ barrel. In the second half of 2014 , the crude oil price dived from the peak price. In 2015 , the crude oil price fell to $\$ 45 \sim 70 /$ barrel. Correspondingly, the National Development and Reform Commission of China announced to improve the wellhead price of natural gas in 2010. From 2010 to 2014, the price of CNG in Sichuan rose to 4 yuan $/ \mathrm{Nm}^{3}$ for the second time. At the same time, the central government issued a financial subsidy policy for electric vehicles. The Sichuan provincial government also introduced $50 \%$ of the financial subsidy policy in comparison with the central government for electric vehicles. However, there were no subsidies in the policies of the central government and the provincial government for $\mathrm{CNG}$ vehicles.

\section{Discussion: The CNG Vehicle IE}

\subsection{Cultivation Path of the CNG Vehicle IE}

According to the Sichuan case, the cultivation path of the CNG vehicle IE was derived and shown in Figure 2.

At the first phase of the cultivation of the CNG vehicle IE, the key point was the innovation of products and complementary products. Enterprises developed reequipping fittings and products of CNG vehicles. They formed product patents and mastered the technologies of CNG filling stations to provide complementary products and were promoted at national and provincial level through the impact of central and local governments. Complementary products indicated that only when the two products work in coordination can they satisfy one demand of consumers. Generally speaking, the increasing price of one product's complementary products because of the decreasing demand of the 
complementary products, will result in the decreasing demand of this product. At the beginning of 2000, Sichuan province constructed 30 CNG filling stations and owned 5000 CNG vehicles [35], which satisfied the consumption demand of CNG vehicles and complementary products and promoted the industrialization of CNG vehicles.

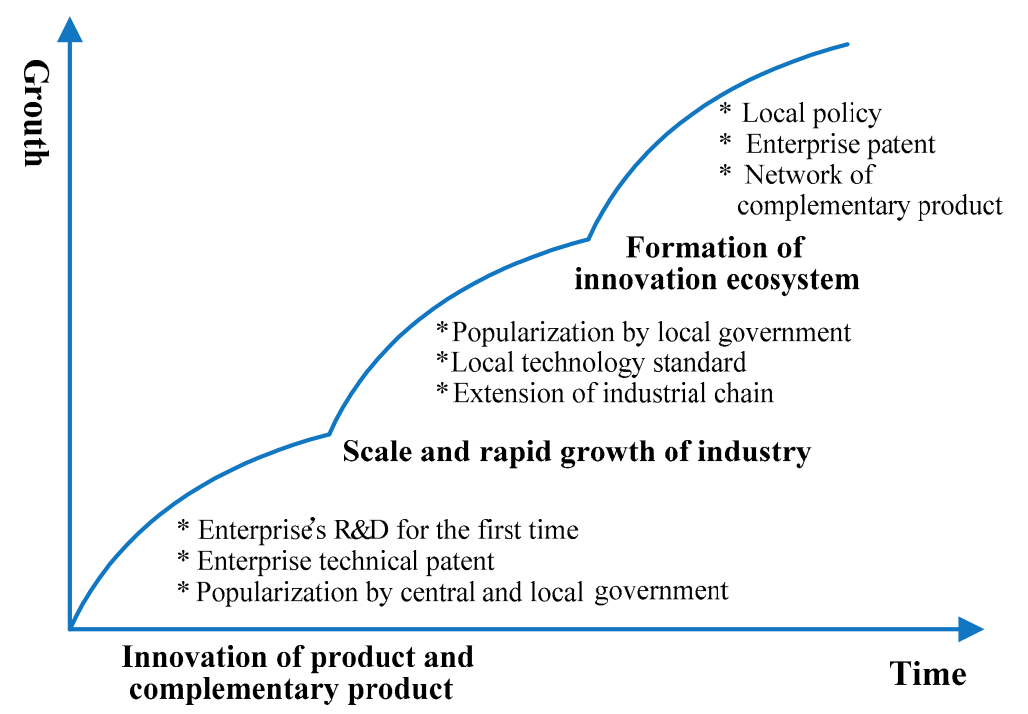

Figure 2. Cultivation path of the CNG vehicle innovation ecosystem.

In the second phase of the cultivation of the CNG vehicle IE, the CNG vehicle industry witnessed a rapid growth. From 2001 to 2005, the Sichuan CNG vehicle industry represented an annual average growth of $10 \%$ [35]. With the regional popularization of local governments, and the formation of the technical standards of products and complementary products, Sichuan CNG vehicles and the complementary products had been large-scaled, which formed a streamlined industrial chain based on researching and manufacturing products and complementary products.

In the third phase of the cultivation of the CNG vehicle IE, CNG vehicles formed an IE through local policies, enterprise patents, and the network of complementary products. In this phase, the Sichuan CNG vehicle industry improved the research and manufacturing of equipment and crucial parts via the processes of introduction, digestion, absorption, and innovation. It formed a relatively complete industrial chain. Nine national achievements, including operational testing and technique examination of CNG vehicles, were approved. Over 20 technical achievements, including the equipment of gas stations, the technology of gas storage wells, and energy-saving compressors, were granted national patents. In 2015, Sichuan CNG IE formed a relatively complete system of gas station construction, vehicle manufacturing, reequipping and equipment manufacturing, and testing service.

\subsection{Symbiosis among the Communities within the CNG Vehicle IE}

The symbiotic process model among communities within the CNG vehicle IE was generalized and shown as Figure 3 from the cultivation process of Sichuan CNG vehicle IE. Inside the CNG vehicle IE, there was a symbiosis among the communities of governments, CNG vehicle product enterprises, CNG complementary products enterprises, and customers. In other words, the strategies among these four communities are not a zero-sum game of innovation performance, but a sum growth improving the innovation performance. 


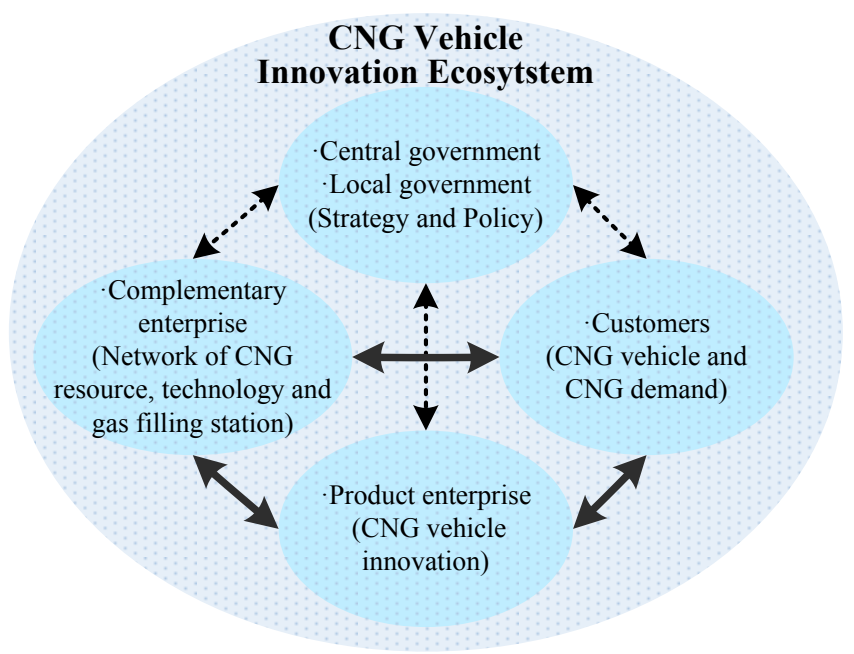

Figure 3. Symbiotic process model among the communities within the CNG vehicle innovation ecosystem.

\subsubsection{Government Community Is a Propeller for Other Communities}

Government community plays a propeller role. First, it promotes the development of CNG vehicle products and complementary products enterprises. The assessment of national new products and the national important popularized technology projects are dominated by central government departments. The popularization of high-tech projects at provincial and national level is also dominated by local government departments. Second, local government departments build the technical standards for CNG vehicles and filling stations. They also approve provincial capitals as national pilot cities. These actions set good examples for the benign development of product enterprises and complementary enterprises. Third, local government departments focus on the price of petroleum and unify the decreasing price of CNG in the province. It expands the demand of CNG vehicles and CNG.

\subsubsection{Product Enterprise Community Is the Focus for Other Communities' Innovation}

The product enterprise community lays stress on product innovation, and is the focus for other communities' innovation. First, according to the literature [30], the local enterprise community was the earliest organization to develop CNG vehicles and obtain national patents in China. Second, the product enterprise community is the dominator of the streamlined service on CNG vehicle $R \& D$ and manufacturing. The product enterprise community mainly engages in CNG vehicle manufacturing, equipment manufacturing, vehicle reequipping and repairing, and so on. Third, the product enterprise community is the dominator of the applied development on CNG vehicle product technology promotion. All of the CNG vehicle aftermarket parts are developed and made by the local product enterprise community.

\subsubsection{Complementary Product Enterprise Community Is the Premise for Other Communities}

The CNG complementary product enterprise community is the premise for other communities due to the network construction of resources, technology, and filling stations. On the one hand, the complementary product enterprise community has the CNG resource cost advantage because of the abundant resources in the local area and the characteristics of volatility and high transportation cost for natural gas. The proven reserves of natural gas in Sichuan is more than 5000 billion normal cubic meters, which takes up 35-50\% of the nation's storage [30]. On the ground of internal survey documents, the total gas output in Sichuan in 2014 was 25.4 billion normal cubic meters. There were 14.3 billion normal cubic meters transferred out of the province, 5.4 billion normal cubic meters moved in from other provinces, and 16.5 billion cubic meters consumed in the local area (the road 
transportation consumption accounted for 4\%). Meanwhile, in the Thirteenth Five-Year Plan, Sichuan has a relatively comprehensive plan for natural gas production. On the other hand, the complementary product enterprise community offers reliable technological guarantee for the development of other communities by means of CNG production, the network construction and distribution of natural gas transmission, and CNG filling stations. According to Sichuan Twelfth Five-Year Energy Plan, in terms of the exploration of natural gas, up to 2015, it would be expected that the accumulative investment would be 32.1 billion yuan. The added ascertained storage of gas was about 1017 billion normal cubic meters within the basin. The key explorations covered six projects: both sides of the Kaijiang-Liangping through exploration project, Yuanba block exploration project, shale gas, and other exploration projects. The gas transmission network in Sichuan and Chongqing was initiated in the 1960s. With the development of natural gas exploration, distribution and transformation of marketing in Sichuan and Chongqing, it has formed a pipe network system combined with large natural gas fields and markets, which consists of gathering pipeline network in the natural gas fields, regional gathering pipeline network and national main pipelines. The total length of the pipes is more than 20,000 kilometers through several dozen years' development and reformation. Because of the highly overlapping feature in the gas fields and gas markets in Sichuan province, most of the gas pipelines possess the outstanding characteristics of the integration of "gas production, gas collection, gas transmission and gas distribution". As to the construction subjects, the gas pipelines in Sichuan are mainly constructed and managed by the oil and gas enterprises belonging to China National Petroleum Corporation and China Petro-Chemical Corporation.

\subsubsection{Customer Community Is a Power Supply for Other Communities}

Customer community is a power supply for other communities, which is mainly reflected in the customer's demand for the high cost performance of the CNG vehicle and CNG. In order to meet this demand as soon as possible, the local product enterprise community has introduced oil-gas (fuel oil and CNG) dual-fuel vehicles. From 2010 to 2015, the average annual share of oil-gas dual-fuel taxis in Sichuan's cities was $77.6 \%$, and the number of the taxis increased year by year. The average annual share of CNG single-fuel taxis was 5.1\%, and the number of CNG single-fuel declined steadily over the past years, as shown in Figure 4.

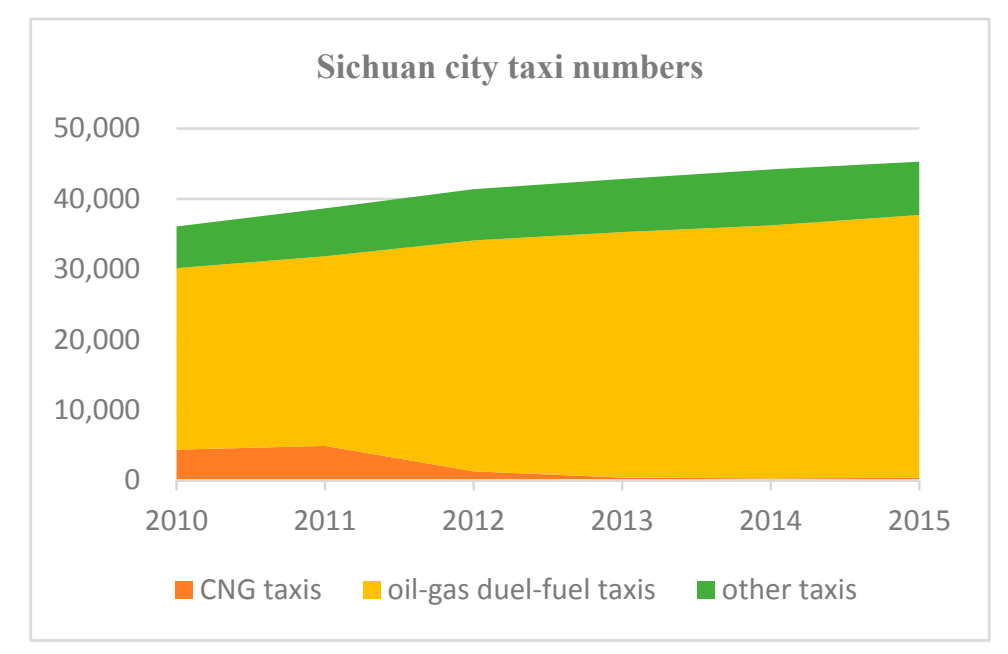

Figure 4. Sichuan city taxi numbers in 2010-2015.

The reasons are as follows: First, the local customer community expects high-cost performance CNG products, which promotes the product enterprise community to develop low-cost CNG vehicle products in a short term. The CNG vehicle reequipping only needs to add CNG cylinders, priced at $¥ 5000$ or so, on a traditional fuel oil vehicle. 
Second, the price ratio of CNG and petroleum fluctuates, which pushes the product enterprise community to develop the oil-gas dual-fuel vehicle products and meet the customers' high-cost performance demand of complementary products. The CNG vehicle industries are developing relatively fast in the areas where CNG price is lower than $60 \%$ price of \#90 gasoline, such as Sichuan, Xinjiang, Shandong province, etc. The CNG vehicle industries are developing extremely fast in areas where CNG prices are 50\% lower than gasoline prices, such as in most of Xinjiang's cities, except Urumqi. For the areas where gas prices are $60 \%$ higher than gasoline prices, CNG vehicle industries are developing slowly. For the areas where gas prices are 70\% higher than gasoline prices, the development of CNG vehicles is almost stagnant.

\subsection{The Substitutability between CNG Vehicle IE and Other Vehicle IEs}

From the cultivation process of CNG vehicles IE in Sichuan province, we can see the substitutive process model between CNG vehicle IE and other vehicle ecosystems as generalized and shown in Figure 5. In the buyer's market environment, the substitutability exists between the IEs which provide similar products between similar product communities and between similar product enterprises. That is to say, even in the innovation performance sum growth of the external buyers' environment (referred in Appendix A), the relationship between CNG vehicle IE and other vehicle IEs is not to improve the total innovation performance jointly, but a game of innovation performance. Consumers are greatly affected by the substitutive IEs in the use stage.

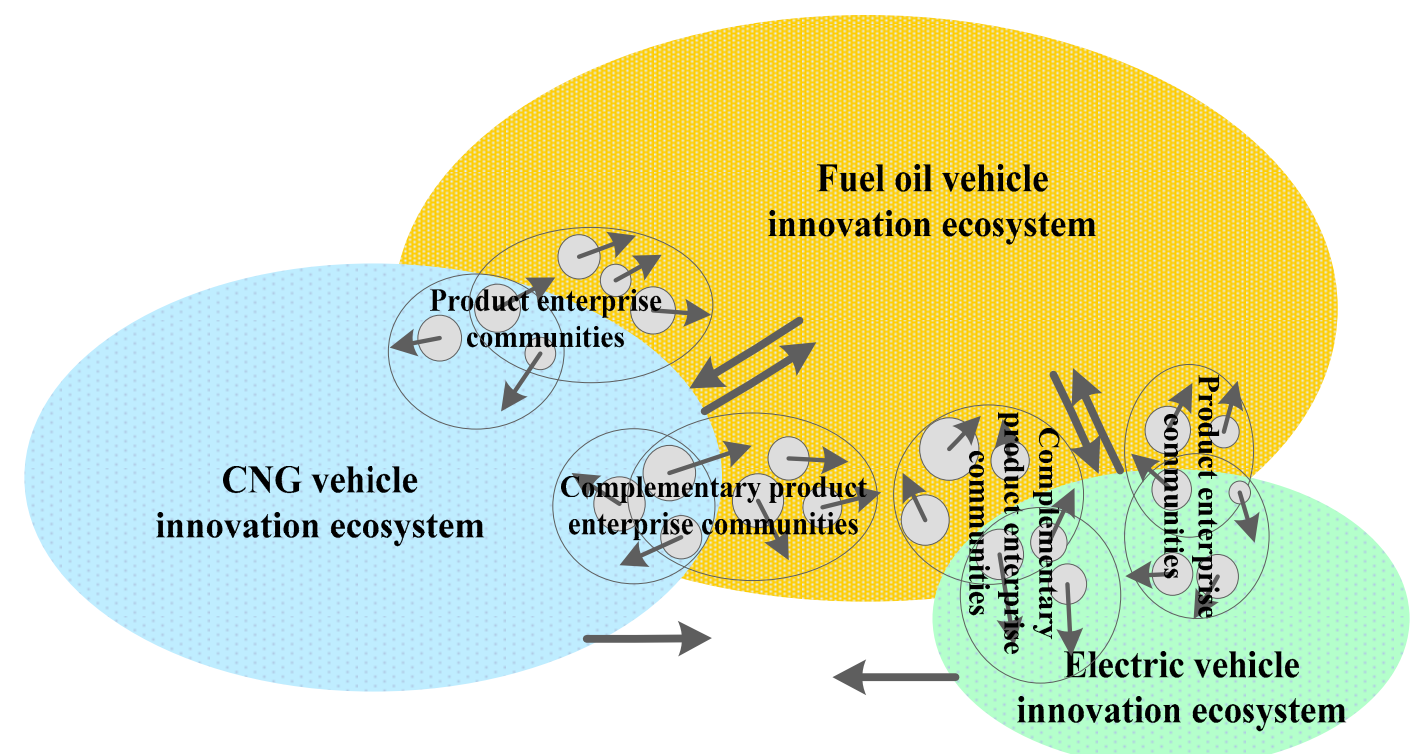

Figure 5. Substitutive process model between CNG innovation ecosystem and other vehicle innovation ecosystems.

\subsubsection{The Substitutability between CNG Vehicle IE and Other Vehicle IEs}

CNG vehicle IE is substitutive to other vehicle IEs. Some scholars believe that CNG vehicle IE is in transition to the counterpart of electric vehicles. This research argues that it is necessary to discuss the problem in light of local conditions. From a long-term perspective, any technology is transitional. From 2010 to 2015, the average annual share of Sichuan fuel vehicle production increased from $41.3 \%$ to $88.6 \%$, which showed a year-by-year trend as shown in Figure 5. The average annual share of oil-gas dual fuel vehicle fell from $58.7 \%$ to $11.2 \%$, manifesting the trend of production fluctuation as shown in Figure 6. The reasons are:

First, the traditional oil fuel vehicle IE quickly took over the local market, driven by the GDP performance of the local government. By 2015, the province had 2 million oil fuel vehicle manufacturing 
capacity and formed a relatively complete product series from the vehicle to the powertrain, key parts, and so on. However, the local matching rate of vehicle manufacturing in Sichuan was less than 30\%. Sichuan had 14 oil vehicle enterprises including FAW-Volkswagen Chengdu branch, Sichuan Hyundai, Sichuan FAW-Toyota, Zhongjia Volvo, and Chuanqi Share, etc. It had nearly 400 oil vehicle components production enterprises and more than 2000 stations (99\% coverage).

Second, the switching cost was lower from fuel to CNG vehicle IE. There were price dividends in consuming CNG for consumers. The local CNG vehicle IE adjusted measures to add the gas station facilities to the petrol stations. The users reequipped the traditional oil fuel vehicles with the installation of CNG cylinders. In this way, the CNG vehicle IE seized the local vehicle market in improving the cost performance according to local conditions.

Third, under the encouragement of the central government and Sichuan provincial government for the electric vehicle subsidies, the local electric vehicle IE also has a strategic commanding position in the local vehicle market by developing pure electric or petrol-electric hybrid vehicles. Sichuan's local vehicle makers, such as Shudu Bus, Yema car, and Yajun van, had been able to seize the commanding heights of strategy of the local electric vehicle market, relying on financial subsidies of central and local governments. Because of the cost factors, such as battery technology, charging infrastructure, and charging time, the switching cost from fuel to electric vehicle is high for consumers.

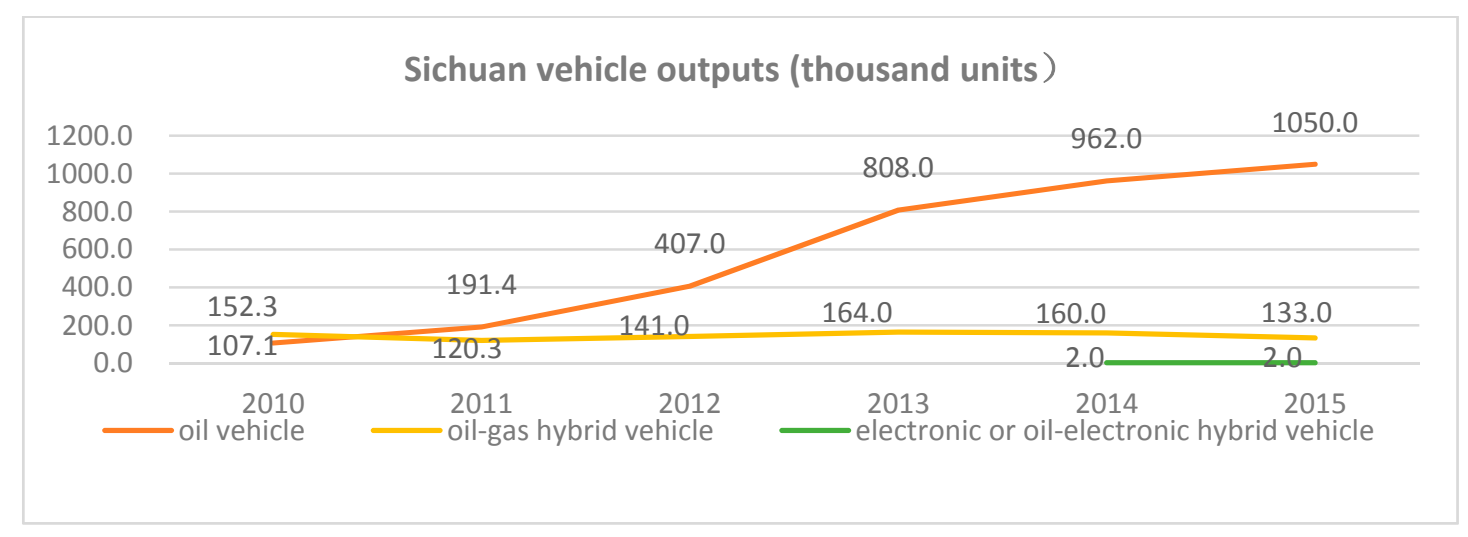

Figure 6. Sichuan vehicle outputs in 2010-2015.

\subsubsection{The Substitutability between the Similar Communities of Vehicle IEs}

The underlying reason for the substitutability between CNG vehicle IE and other vehicle IEs is the substitutability between the similar communities of their vehicle IEs. The substitutability of customers' demand on power sources such as oil, gas, electricity, etc. results in the substitutability between the vehicle product enterprise communities and between the complementary product enterprise communities of oil-, gas-, and electricity-powered vehicles, etc. The discussion takes the Sichuan city bus as an example (referring to Figure 7). Fuel prices continuously rose from 2010 to 2014. As a result, the number of CNG buses in Sichuan grew at an annual rate of $12.1 \%$. From the second half of 2014, petroleum prices plunged from a high level. As a result, the number of CNG and oil-gas hybrid buses in Sichuan province declined significantly in 2015, while the number of oil buses continued to rise. 


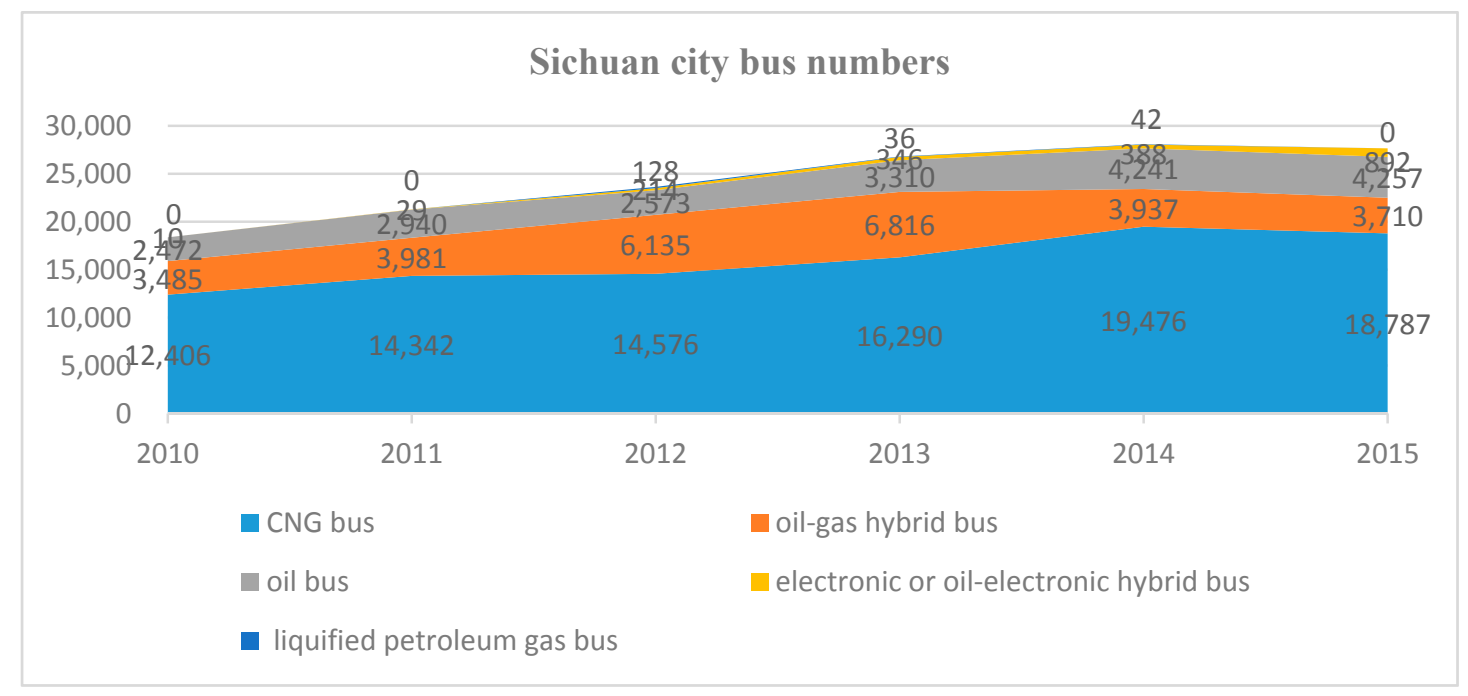

Figure 7. Sichuan city bus numbers in 2010-2015.

\subsubsection{The Substitutability between the Enterprises in the Communities of CNG Vehicle IE}

There are two aspects of the substitutability between the enterprises in the communities of CNG vehicle IE. First, within the product enterprise community of the CNG vehicle IE, the enterprises that provide similar CNG products exclude each other. In Chengdu, Sichuan, for example, there are 19 CNG vehicle reequipping enterprises in the city, including six first-class repairing enterprises with road transportation operation permits, and 13 second-class repairing enterprises with road transportation operation permits. All of the 19 enterprises may engage in $\mathrm{CNG}$ vehicle modification. These enterprises supplied similar product reequipping service in adjacent areas. As a customer chooses one enterprise of CNG vehicle modification services, they cannot choose other enterprises, so these enterprises exclude each other.

Second, within the complementary product enterprise community of the CNG vehicle IE, the enterprises that provide similar CNG complementary products exclude each other because of the overcapacity. This research takes the conventional natural gas exploration enterprises in Sichuan province as an example. The current natural gas development enterprises in Sichuan mainly include the southwest oil and gas field branch of China National Petroleum Corporation (CNPC), the southwest oil and gas field branch and the Zhongyuan Puguang branch of China Petro-Chemical Corporation (Sinopec). In 2015, the oil and gas fields of the southwest oil and gas branch of CNPC produced 15.67 billion normal cubic meters of natural gas. The annual production of natural gas reached a record of 350 million normal cubic meters higher than the earlier record. In 2015, the southwest oil and gas branch of Sinopec produced 4.825 billion normal cubic meters of natural gas, an increase of 1.45 billion normal cubic meters more than in 2014. The Zhongyuan Puguang branch of Sinopec recently had 52 development wells, with a daily production of 12-13.5 million normal cubic meters of mixed natural gas and average 10 million normal cubic meters of natural gas transported per day. Because of the current overcapacity of natural gas in Sichuan, these three natural gas development enterprises exclude each other.

\section{Conclusions: Theoretic, Practical Significance and Policy Implication}

By studying the CNG vehicle IE in Sichuan province of China, this research provides important theoretical, practical and political reference value to cultivate alive IE in emerging markets, and to achieve energy security and emission reduction for regional vehicle IEs with resource advantages. 


\subsection{Theoretical Significance}

The theoretical significance of this study mainly includes three aspects: Firstly, because the research on the cultivation of innovative ecosystem in a region with rich resources needs more theoretical contributions, this study generalizes a feasible cultivation path of CNG vehicle IEs. By tracing back the history of three phases of the cultivation of the CNG vehicle IE in Sichuan province, it is revealed that the cultivation path of the CNG vehicle IE can be divided into three phases, which consists of products and complementary products innovation, scale and rapid growth of industry, and the formation of IE.

Secondly, this study deduces the symbiotic process model among communities within the CNG vehicle IE (see Figure 3). It reveals the symbiosis among the communities of CNG vehicle product enterprises, CNG complementary products enterprises, customers, and governments within the CNG vehicle IE. Its essence is to create an "ecological environment" which connects the strategies and policies of the government, product innovation of product enterprises, resource supply of complementary product enterprises, and product and complementary product demands of customers in the process of industrialization of technological achievements. This ecological environment helps to improve the system of product innovation and complementary product network. Without this vibrant ecological environment, the innovation may fall into the "valley of death" at any time.

Thirdly, it deduces the substitutive process model between CNG vehicle IE and other vehicle IEs (see Figure 5). The CNG vehicle IE is substitutive to the traditional fueled vehicle IE and the electric vehicle IE. There is also substitutability between their product enterprise communities and between the complementary product enterprise communities. Moreover, there is substitutability between similar product enterprises and between complementary product enterprises of the CNG vehicle IE. In brief, the substitutability appears between the IEs that provide similar products, between the similar product communities and between the similar product enterprises.

\subsection{Practical Significance}

The important practical significance is to guide the resource-rich areas' governments and enterprises to cultivate IEs based on the characteristics of symbiosis and substitutability of IE, which guides the emerging market enterprises in resource-rich areas to obtain the sustainable innovation ability. In addition, in tracking the practitioners and characteristics of CNG vehicle industrial expansion from the initial phase to the phase of formation of IE similar to "tropical rain forest", this study helps future practitioners manage the expansion of enterprises and industries in different stages. When practitioners meet difficulties in expansion, they may use the process models in this paper as detailed road signs, which may identify the appropriate corrective measures. Thus, they may try their best to use the largest resources and capacity to invest in the management of technology and market oriented enterprises so as to reach maximum potential.

\subsection{Policy Implication}

Emerging industry development always requires some first impetus, either market price dividend, government policy promotion, or enterprise technological innovation. The Sichuan CNG vehicle industry developed from the rich energy and cheap price, low switching cost of the vehicle, and more surplus for consumers. Therefore, the CNG vehicle IE rode on a momentum. These driving factors are universal, which is of great significance to the future development of emerging industries. As a result of the symbiosis and the substitutability of IE, the government needs to formulate the top design based on local resources, guide innovation, and reduce the resource consumption and internal friction. To achieve the domain position of the local CNG vehicle IE, the government may start from the following several aspects.

First, the innovation policy for cultivating CNG vehicle IE needs to be adjusted with local conditions as the development of any IE is rooted in the local context. Sichuan has abundant natural gas, 
low price, and dense distribution of gas transmission pipelines, offering a natural resource advantage for complementary product enterprise populations of the CNG vehicle IE. Sichuan may absorb the natural gas overcapacity by using the CNG vehicle IE to surpass the traditional oil vehicle ecosystem.

Second, the government should strictly implement the policy of low oil consumption, forcing traditional oil fuel vehicle IE to transform and striving to develop the CNG vehicle IE. Under the squeezing of future fuel policies, there will be no way for enterprises still running in the path of traditional vehicles. On 1 January 2016, the "Average Fuel Consumption Evaluation Method and Index" (GB 27999 of 2014) was implemented. According to the requirements of the Chinese government, the average fuel consumption of all enterprises' passenger vehicles must decline from $6.9 \mathrm{~L} / 100 \mathrm{~km}$ in 2015 (the third stage) to $5.0 \mathrm{~L} / 100 \mathrm{~km}$ by 2020 (the fourth stage). Therefore, it is feasible for enterprises to develop CNG vehicles and other clean energy vehicles based on the resource advantages of Sichuan.

Third, the government ought to promote the special engines of CNG vehicles and reduce the sulfur content in the $\mathrm{CNG}$, therefore, the product enterprise can form joint force to promote deeper technology innovation and develop high performance products of CNG vehicles. Sichuan shall tap the potential of energy conservation and emissions reduction. Currently, Sichuan is promoting CNG cylinder technology. However, the special engines for CNG vehicles has not been widely promoted. On one hand, special engines will improve the combustion adequacy and dynamic performance of $\mathrm{CNG}$ vehicles. On the other hand, the sulfide of CNG has a corrosive effect on the CNG vehicle engines, which increases the maintenance cost of the vehicle and reduces the life of the vehicle.

Acknowledgments: The research was funded by the project of China Postdoctoral Science Foundation (2016M591197), and the project of National Natural Science Foundation of China (71172176, 71172004). This paper had been presented at SOItmC 2017. The authors have carefully and fully developed this study based on the great comments from the conference.

Author Contributions: Ling Ding wrote all of this paper, from the building of the research framework to the analysis; she is the first author. Jinxi Wu proposed important amendments for this research; he is the corresponding author.

Conflicts of Interest: The authors declare no conflict of interest.

\section{Appendix A}

According to the data from the National Bureau of Statistics of China, the past 25 years witnessed more than 10\% high-speed growth of Sichuan civil vehicles except the past five years (see Figure A1).

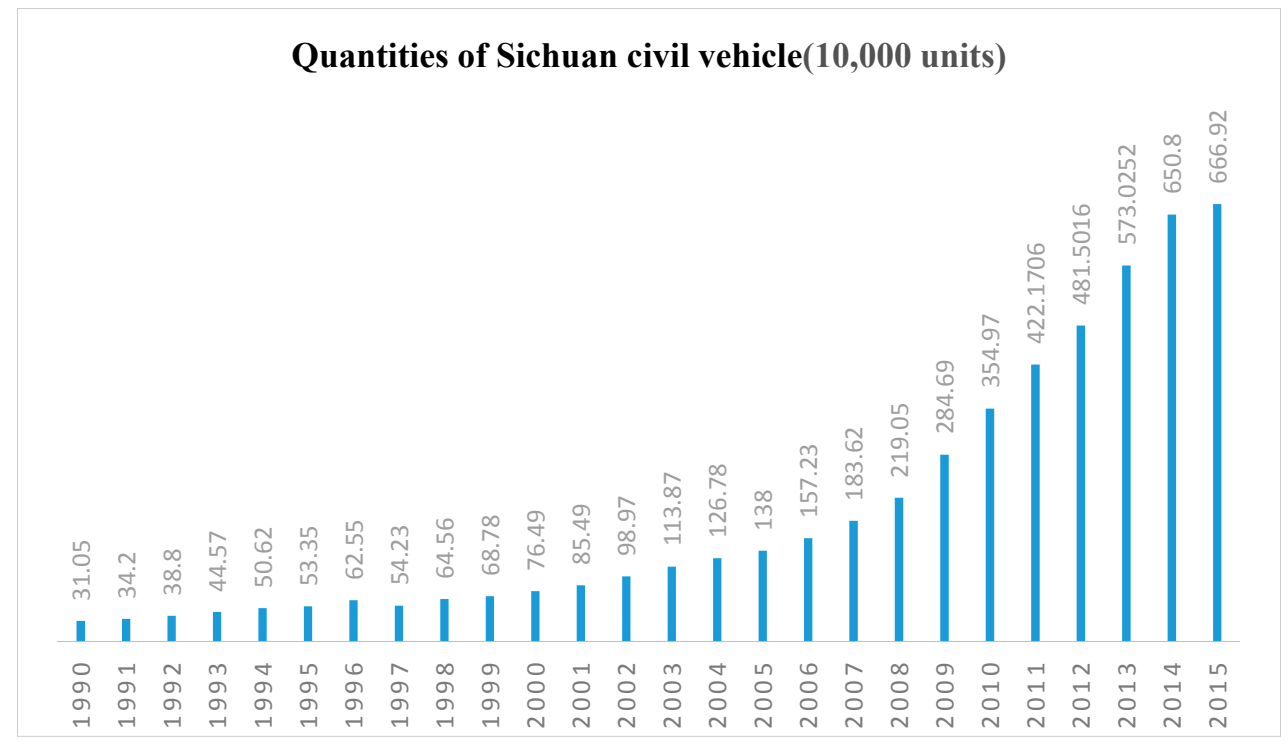

Figure A1. Quantities of Sichuan civil vehicle in 1990-2015 (10,000 units). 


\section{References}

1. Hwang, V.W.; Horowitt, G. Silicon Valley Ecosphere: Innovative Rainforest Laws; China Machine Beijing Press: Beijing, China, 2015.

2. Feng, W. Interaction between industrial agglomeration and circular economy. China Popul. Resour. Environ. 2008, 18, 166-172.

3. Adner, R. Match your innovation strategy to your innovation ecosystem. Harv. Bus. Rev. 2006, 84, 98-107. [PubMed]

4. Luoma-aho, V.; Halonen, S. Intangibles and innovation: The role of communication in the innovation ecosystem. Innov. J. 2010, 7, 1-20.

5. Zahra, S.A.; Nambisan, S. Entrepreneurship in global innovation ecosystems. AMS Rev. 2011, $2011,4-17$. [CrossRef]

6. Adner, R.; Kapoor, R. Value creation in innovation ecosystems: How the structure of technological interdependence affects firm performance in new technology generations. Strateg. Manag. J. 2010, 31, 306-333. [CrossRef]

7. Zeng, G.; Gou, Y.; Liu, L. From innovation system to innovation ecosystem. Stud. Sci. Sci. 2013, 1, 4-12.

8. Rohrbeci, R.; Hölzle, K.; Gemünden, H.G. Opening up for competitive advantage-How Deutsche Telekom creates an open innovation ecosystem. RED Manag. 2009, 39, 420-430.

9. Birol, M.; Göktas, D. Components of innovation ecosystems: A cross-country study. Int. Res. J. Financ. Econ. 2011, 76, 102-112.

10. Rubens, N.; Still, K.; Huhtamaki, J.; Russell, M.G. A network analysis of investment firms as resource routers in Chinese innovation ecosystem. J. Softw. 2011, 6, 1737-1745. [CrossRef]

11. Curley, M.; Salmelin, B. Open Innovation 2.0: A New Paradigm; OISPG White Paper; European Commission: Brussels, Belgium, 2013; pp. 1-12.

12. Gray, B.; Bayley, S. Case Study: Shelter Innovation Ecosystem; Working Paper for the Humanitarian Innovation Ecosystem Project; University of Brighton: Brighton, UK, 2015.

13. Autio, E.; Kenney, M.; Mustar, P.; Siegel, D.; Wright, M. Entrepreneurial innovation: The importance of context. Res. Policy 2014, 43, 1097-1108. [CrossRef]

14. Hansen, M.T.; Mors, M.L.; Løvås, B. Knowledge sharing in organizations: Multiple networks, multiple phases. Acad. Manag. J. 2005, 48, 776-793. [CrossRef]

15. Gawer, A.; Cusumano, M.A. Industry platforms and ecosystem innovation. J. Prod. Innov. Manag. 2014, 31, 417-433. [CrossRef]

16. Zhang, W.; Karimi, H.R.; Zhang, Q.; Wu, S. Collaborative development planning model of supporting product in platform innovation ecosystem. Math. Probl. Eng. 2014. [CrossRef]

17. Arimoto, T.; Levien, R. Strategy as Ecology. Harv. Bus. Rev. 2004, 4, 51-62.

18. Engler, J.; Kusiak, A. Modeling an innovation ecosystem with adaptive agents. Int. J. Innov. Sci. 2011, 3, 55-68. [CrossRef]

19. Liu, H.; Hu, Y.; Ma, W. Ecological system suitability of regional innovation and correlation of economic development. Chin. J. Manag. Sci. 2013, 2, 764-770.

20. Liu, D.; Yan, C. Research on the structure and mechanism of collaborative innovation network. Manag. World 2013, 12, 1-4.

21. Wu, J. Innovation Ecosystem Theory; Tsinghua University Press: Beijing, China, 2015.

22. Rabelo, R.J.; Bernus, P. A holistic model of building innovation ecosystems. IFAC PapersOnLine 2015, 48, 2250-2257. [CrossRef]

23. Li, H.; Song, J. Integration and evolution of innovation ecosystem resources: A case study on China's industry technology innovation strategic alliance. China Soft Sci. 2014, 2, 129-141.

24. Walsham, G. Interpretative case studies in IS research: Nature and method. Eur. J. Inf. Syst. 1995, 4, 74-81. [CrossRef]

25. Eisenhardt, K. Case Study Research Method: Selected Articles; Peking University Press: Beijing, China, 2012.

26. Patton, M.Q. How to Use Qualitative Methods in Evaluation; Sage Publications: Thousand Oaks, CA, USA, 1987.

27. Glaser, B.G.; Strauss, A.L. The Discovery of Grounded Theory: Strategies for Qualitative Research; Transaction Publishers: Piscataway, NJ, USA, 2009.

28. Yin, R.K. Case Study Research: Design and Methods; Sage Publications: London, UK, 2013. 
29. Pan, S.L.; Tan, B. Demystifying case research: A structured-pragmatic-situational (SPS) approach to conducing case studies. Inf. Organ. 2011, 21, 161-176. [CrossRef]

30. Zou, K. Development of CNG vehicle to be speeded up in Sichuan. Nat. Gas Oil 1996, 14, 53-57.

31. Wu, Y. Imperative development of compressed natural gas (CNG) automobile. Nat. Gas Ind. 1994, 14, 81.

32. Chen, G. Information compilation of natural gas vehicle industry. Nat. Gas Ind. 1996, 16, 113.

33. Guo, F.; Huang, M. UNDERGROUND storage of compressed natural gas. Nat. Gas Ind. 1996, 16, 102-103.

34. Bian, X. Development of China's gas-fuelled automobiles: Current situation and prospects for the 10th five-year plan period. Int. Petrol. Econ. 2001, 9, 35-37.

35. Yao, S.; Zhang, C.; Huang, H.; Li, Y.; Liu, Z. Profit assessment of the intercity transportation of CNG vehicles in Sichuan province and some proposals for promoting its practical application. Nat. Gas Ind. 2012, 32, 104-107.

36. Yang, J.; Li, Y.; Huang, H. Research of CNG/gasoline dual fuel vehicle emissions based on measurements of double idle speed. Small internal combustion engine and motorcycle. China Acad. J. 2012, 41, 32-35.

(C) 2017 by the authors. Licensee MDPI, Basel, Switzerland. This article is an open access article distributed under the terms and conditions of the Creative Commons Attribution (CC BY) license (http:/ / creativecommons.org/licenses/by/4.0/). 